\title{
Design and application of a Staphylococcus-specific single strand conformation polymorphism-PCR analysis to monitor Staphylococcus populations diversity and dynamics during production of raw milk cheese
}

\author{
C. Delbès and M.-C. Montel \\ Unité de Recherches Fromagères, INRA, Aurillac, France \\ 2004/0722: received 23 June 2004, revised and accepted 1 March 2005
}

\begin{abstract}
C. DELBÈS AND M.-C. MONTEL. 2005.
\end{abstract}

Aim: Development of a nested-PCR single strand conformation polymorphism (SSCP) assay targeting the $16 \mathrm{~S}$ rRNA genes of the Staphylococcus genus, to monitor staphylococci in cheese.

Methods and Results: New primer sets to specifically amplify 16S rDNA of staphylococci were designed to be used in a nested-PCR SSCP assay. The method was efficient in discriminating the staphylococcal species most frequently found in cheese. It was validated by monitoring Staphylococcus populations in three productions of raw milk cheese. Analysis of milk samples revealed dominant SSCP peaks corresponding to Staphylococcus aureus, Staphylococcus equorum and Staphylococcus saprophyticus. After $12 \mathrm{~h}$, the $S$. aureus peak became dominant. Conclusions: The combination of specific Staphylococcus nested-PCR and SSCP allows rapid and direct monitoring of staphylococci diversity and dynamics in milk and cheese. In the core of the cheeses studied, $S$. aureus may have ecological advantages against other Staphylococcus populations.

Significance and Impact of the Study: This approach is a promising tool to study the ecology of staphylococci in cheeses and in other food samples.

Keywords: 16S rRNA gene, cheese, nested-PCR, single strand conformation polymorphism, Staphylococcus.

\section{INTRODUCTION}

Staphylococci are of the utmost interest for microbiological safety and quality of traditional cheeses. Coagulase-positive staphylococci such as Staphylococcus aureus can produce enterotoxins in foods and may cause toxic infections (Meyrand et al. 1998). Many other staphylococcal species such as Staphylococcus equorum, Staphylococcus xylosus, Staphylococcus vitulinus, Staphylococcus lentus, S. fleurettii and Staphylococcus saprophyticus are also found in dairy products (Devriese and De Keyser 1980; Vernozy-Rozand et al. 1996) and can be important in the cheese ripening process (Irlinger et al. 1997). Food derived S. aureus strains have been intensively studied. However, only limited

Correspondence to: Céline Delbès, Unité de Recherches Fromagères, INRA,

36 rue de Salers, 15000 Aurillac, France (e-mail: cdelbes@clermont.inra.fr).

() 2005 The Society for Applied Microbiology information is available concerning the ecology of staphylococci populations in cheeses and especially in the core of cheeses.

The PCR-based methods targeting 16S-23S rRNA spacer (Couto et al. 2001) or 16S rRNA gene (Mason et al. 2001; Vandecasteele et al. 2001) were used to identify isolates of staphylococcal human or animal infections. However, methods based on the isolation of staphylococci remain too time-consuming to follow populations dynamics. A few culture-independent studies have been carried out on the microbial diversity of dairy products by using molecular techniques targeting $16 \mathrm{~S}$ rDNA, such as denaturing gradient gel electrophoresis (DGGE) (Coppola et al. 2001; Randazzo et al. 2002; Ercolini et al. 2003), temporal temperature gradient gel electrophoresis (Ogier et al. 2002), and recently single strand conformation polymorphism (SSCP) analysis was applied to describe the bacterial 
community dynamics during the production of RDO Salers cheese (Duthoit et al. 2003). Duthoit et al. (2003) highlighted the need for a strategy to point out subdominant populations. Staphylococci can remain undetected on bacterial DGGE or SSCP patterns, although they have been recovered from culture plates (Duthoit et al. 2003; Ercolini et al. 2003).

To our knowledge, no direct method for ecology studies of staphylococci in food products has yet been proposed. The objective of the present study is the development of a Staphylococcus genus-specific SSCP-PCR assay based on $16 \mathrm{~S}$ rRNA gene analysis. The method was validated by investigating the diversity and dynamics of staphylococci during the production and ripening of cheese made from raw milk.

\section{MATERIALS AND METHODS}

\section{Milk and cheese samples}

Cheese productions chosen for this study are artisanal farmhouse productions of a noncooked semi-hard cheese variety made from cow raw milk. A commercial starter culture was added to the milk along with calf rennet. Coagulation proceeded for about 45 min then the curd was cut, filled into moulds and prepressed to remove the whey. Then, $20 \mathrm{~g}$ of salt were added to each cheese and pressing was carried out for about $10 \mathrm{~h}$. Ripening took place at about $10^{\circ} \mathrm{C}$ and $96 \%$ relative humidity for 28 days. Milk and cheese samples were collected in three farms named SA1, SA2 and SA3. Samples were taken aseptically from raw milk, coagulated milk, 12-h cheese, and then from cheese at 1, 5 and 28 days. In each farm, three cheeses from the same production batch were sampled at each stage and the rind was discarded. All samples were stored at $-20^{\circ} \mathrm{C}$ for further bacteriological and molecular analyses.

\section{Enumeration of coagulase-positive Staphylococcus in milk and cheese}

Cheese samples were emulsified in sterile phosphate buffer, diluted, plated on rabbit plasma fibrinogen (RPF) agar (EN ISO 6888-2, De Buyser et al. 2003) and incubated for $24 \mathrm{~h}$ at $37^{\circ} \mathrm{C}$

\section{Extraction of total bacterial DNA from milk and cheese}

Total bacterial DNA was extracted by a phenol-based method as previously described (Duthoit et al. 2003), starting from $1 \mathrm{ml}$ of milk or $1 \mathrm{~g}$ of cheese. Cells lysis was performed by blending sample with zirconium beads in a reciprocating shaker and heating at $80^{\circ} \mathrm{C}$.

\section{Specific amplification of Staphylococcus 16S rRNA gene and SSCP-PCR}

The primer Staph 69B (5'-GAACRGAYRAGRAGCTTG$3^{\prime}$ ), specific for the Staphylococcus genus, was selected from a conserved region at the $5^{\prime}$ end of the $16 \mathrm{~S}$ rRNA gene on the basis of sequences of 32 most frequent Staphylococcus species available in databases (Genbank and RDP) (Maidak et al. 1999). The specific primer Staph $1416 \quad\left(5^{\prime} \mathrm{GA}\right.$ AGCCGGTGGAGTAACCA-3') was adapted from Vandecasteele et al. (2001).

The primer set Staph 69B degenerated/Staph 1416 was used to amplify the 16S rRNA gene of Staphylococcus. The amplification was carried out in a volume of $25 \mu \mathrm{l}$ containing: $1 \mu \mathrm{l}$ of genomic DNA solution (2-10 ng of DNA extracted from milk or cheese), 1X PCR reaction buffer, $200 \mu \mathrm{mol} \mathrm{l}^{-1}$ of each dNTP, $2 \mathrm{mmol} \mathrm{l}^{-1} \mathrm{MgCl}_{2}$, $0 \cdot 3 \mu \mathrm{mol} \mathrm{l}^{-1}$ of Staph 1416, $1 \mu \mathrm{mol} \mathrm{l}^{-1}$ of Staph 69B degenerated and 0.2 U Taq DNA polymerase (Qbiogene, Montréal, Canada). The PCR was performed under the following conditions: 3 min initial denaturation at $94^{\circ} \mathrm{C}$; 35 cycles of denaturation $\left(30 \mathrm{~s}\right.$ at $\left.94^{\circ} \mathrm{C}\right)$, annealing $(30 \mathrm{~s}$ at $60^{\circ} \mathrm{C}$ ) and extension $\left(1 \mathrm{~min} 30 \mathrm{~s}\right.$ at $\left.72^{\circ} \mathrm{C}\right)$; a final extension at $72^{\circ} \mathrm{C}$ for $10 \mathrm{~min}$. After amplification, the PCR product was purified with the StrataPrep PCR purification kit as specified by the manufacturer (Stratagene, La Jolla, CA, USA).

For SSCP-PCR, owing to the sensitivity of SSCP to single-base changes, a nondegenerated version of primer Staph 69B (Staph 69B NED; 5'-GAACA GATGAGGAGCTTG-3') was used along with the primer V2R HEX (5'-ACTGCTGCCTCCCGTAG-3') in a seminested PCR to amplify the V2 region of the $16 \mathrm{~S}$ rRNA gene of staphylococci. The primers were labelled with 5 'fluorescein phosphoramidite: NED for Staph 69B and hexachloro derivative of fluorescein for V2R. The amplification reaction contained $1 \mu \mathrm{l}$ of purified PCR product, 1X PCR reaction buffer, $200 \mu \mathrm{mol} \mathrm{l}^{-1}$ of each dNTP, $2 \mathrm{mmol} \mathrm{l}^{-1} \mathrm{MgCl}_{2}$, $0.5 \mu \mathrm{mol}^{-1}$ of each primer and 1.25 U Pfu Ultra DNA polymerase (Stratagene). The PCR was performed under the following conditions: $3 \mathrm{~min}$ at $96^{\circ} \mathrm{C} ; 25$ cycles of $30 \mathrm{~s}$ at $96^{\circ} \mathrm{C}, 30 \mathrm{~s}$ at $60^{\circ} \mathrm{C}$ and $45 \mathrm{~s}$ at $72^{\circ} \mathrm{C}$; a final extension at $72^{\circ} \mathrm{C}$ for $10 \mathrm{~min}$. Quality of the amplification products was checked on $1.5 \%(\mathrm{w} / \mathrm{v})$ agarose gel before SSCP electrophoresis.

\section{Staphylococcus strains used as references for SSCP analysis}

Fourteen strains belonging to different species of the Staphylococcus genus which can be found in milk and cheese ecosystems were selected: S. xylosus (CIP 8166 T), $S$. vitulinus (ATCC 51145T), S. equorum (CIP 103502 T), 
S. lentus (CIP 8163 T), S. fleurettii (CIP 106114), S. saprophyticus (CIP 76125 T), Staphylococcus cohnii (DSM 20260), Staphylococcus simulans (DSM 20322), Staphylococcus capitis (DSM 20326), Staphylococcus sciuri (DSM 20345), Staphylococcus schleiferi (DSM 6628), Staphylococcus hyicus (DSM 20459), S. aureus subsp. anaerobius (DSM 20714) and S. aureus subsp. aureus (CNRZ 873) strains were obtained from the Collection Institut Pasteur, Paris, France (CIP), the American Type Culture Collection, Rockville, MD, USA (ATCC), the Deutsche Sammlung von Mikroorganismen und Zellkulturen GmbH, Braunschweig, Germany (DSMZ) and the Centre National de Recherches Zootechniques, INRA, Jouy-en-Josas, France (CNRZ). Genomic DNA from these strains was isolated from $5 \mathrm{ml}$ of fresh brain-heart infusion cultures by a phenolbased method as described above. In order to prepare a mixture of equal amounts of genomic DNA from each strain, DNA was quantified with PicoGreen (Molecular Probes, Eugene, OR, USA) on a fluorimeter as specified by the manufacturer.

\section{SSCP electrophoresis}

The SSCP-PCR products were analysed on an ABI Prism 310 Genetic Analyzer (Applied Biosystems, Applera, Foster City, CA, USA) as previously described (Duthoit et al. 2003).

\section{Partial sequencing of nested-PCR clones and $16 S$ rRNA gene of Staphylococcus isolates}

The nested SSCP-PCR reaction was performed with unlabelled primers as described above and the PCR product was ligated in pCR4Blunt-TOPO vector and transformed into Escherichia coli TOP10 OneShot cells as specified by the manufacturer (Invitrogen, Carlsbad, CA, USA). The $450 \mathrm{bp}$ of the $5^{\prime}$ ends, comprising the V2 region, of the $16 \mathrm{~S}$ rRNA gene of clone inserts and isolates were sequenced by using the dye-terminator cycle sequencing ready reaction kit with AmpliTaq DNA polymerase FS (Applied Biosystems) and an ABI Prism 310 Genetic Analyzer (Applied Biosystems). Each sequence obtained was compared with sequences available in databases (Genbank and RDP) (Maidak et al. 1999).

\section{RESULTS}

\section{Semi-nested PCR and SSCP analysis}

New primer sets to specifically amplify $16 \mathrm{~S}$ rDNA of staphylococci in complex microbial ecosystems and especially in cheese were designed. The first primer set, Staph69B-Staph 1416 allowed amplification of almost the whole 16S rRNA gene. The optimal annealing temperature was empirically determined by raising the temperature in steps of $1^{\circ} \mathrm{C}$ from 56 to $66^{\circ} \mathrm{C}$ and was found to be $60^{\circ} \mathrm{C}$. At this temperature, a 1400-bp amplicon was obtained with DNA from the 14 Staphylococcus strains tested. A range of nontarget bacteria found in cheese (Streptococcus thermophilus, Lactococcus lactis, E. coli and Macrococcus caseolyticus) was tested to evaluate the specificity of the primers and gave negative results after 35 PCR cycles. This primer set was used in a 35-cycle PCR assay on DNA extracted from milk with low levels of staphylococci $\left(<100 \mathrm{CFU} \mathrm{ml}^{-1}\right)$. No amplicon could be detected on an agarose gel. Hence, staphylococci were under the detection limit of this first PCR but no other species from cheese was amplified after 35 cycles. To improve the sensitivity of the assay for low levels of staphylococci and to generate an amplicon convenient for analysis by SSCP, a semi-nested PCR was performed. The first amplicon was purified in order to remove all remaining oligonucleotides and then served as a template during the semi-nested PCR step using the nondegenerated genus-specific primer Staph 69B NED and a bacterial primer V2R HEX to amplify the V2 region of staphylococcal $16 \mathrm{~S}$ rDNA.

Figure 1 shows the fingerprints obtained after specific amplification of $16 \mathrm{~S}$ rDNA of staphylococci via the two PCR steps and SSCP analysis. A 200-bp amplicon was obtained with all of the 14 Staphylococcus species used as references and most of them gave rise to distinguishable patterns with the forward strand of the amplicon labelled with Staph 69B-NED, except $S$. cohnii and $S$. hyicus that

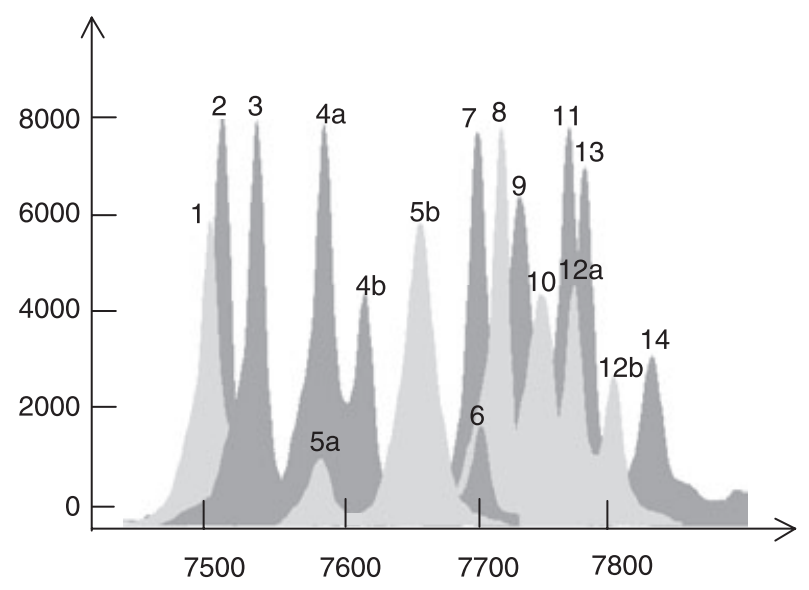

Fig. 1 SSCP analysis of PCR-amplified 16S rRNA gene fragments from reference strains of staphylococci. Comparison of patterns of individual species (forward strand of amplicon). Peak number 1 : Staphylococcus vitulinus; 2: S. sciuri; 3: S. fleuretti; 4a,b: S. lentus; 5a,b: S. aureus; 6: S. hyicus; 7: S. cohnii; 8: S. aureus subsp. anaerobius; 9: S. schleiferi; 10: S. capitis; 11: S. xylosus; 12a,b: S. saprophyticus; 13: $S$. equorum; 14: $S$. simulans. $y$ axis: fluorescence intensity; $x$ axis: elution in scans (unit of GeneScan software) 


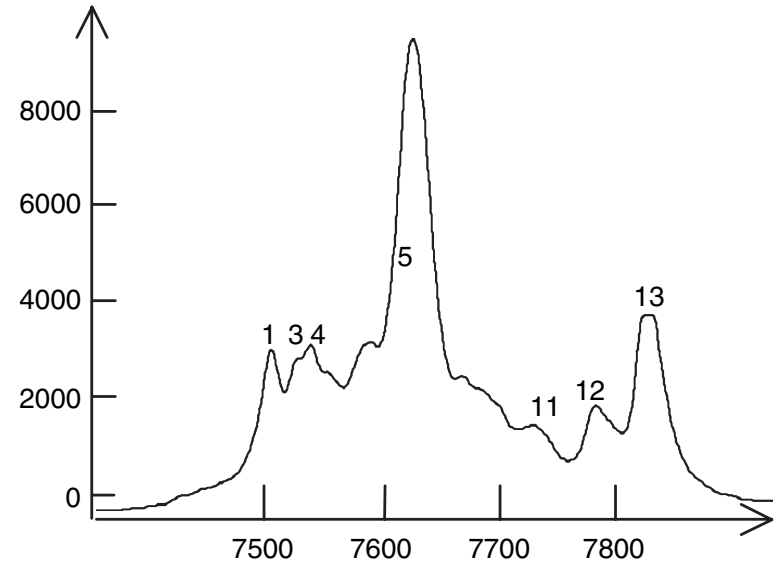

Fig. 2 SSCP pattern obtained after amplification of a mixture of equal amounts of DNA from seven species (forward strand of amplicon). Correspondence between peak numbers and species: see legend of Fig. 1

co-eluted (Fig. 1). Some strains, such as $S$. aureus subsp. aureus and S. lentus, showed a two-peak pattern. Patterns obtained with the reverse strand (labelled with V2R-HEX) allowed discrimination between $S$. cohnii and $S$. hyicus but showed comigration of the peaks of $S$. aureus and $S$. equorum (data not shown). Consequently, for milk and cheese analysis, only patterns obtained with the forward strand (Staph 69B labelled with NED) are shown. The discriminatory potential of the semi-nested SSCP-PCR was further validated on an artificial mixture of equal amounts of total DNA (5 ng each) from seven strains frequently found in cheese (Fig. 2). All seven strains were successfully detected; however, a higher signal corresponding to the $S$. aureus pattern was noticed.

\section{Diversity and dynamics of Staphylococcus populations during manufacture and ripening of cheeses of three farms}

The growth kinetics of coagulase-positive staphylococci during cheese making and ripening was determined by enumeration on RPF agar. Coagulase-positive staphylococci reached their maximum in $12-\mathrm{h}$-old cheese, with an increase of $1.3 \log _{10}, 1.7 \log _{10}$ and $2 \log _{10}$ in SA1, SA2 and SA3 cheeses, respectively, from the count in raw milk to the count at $12 \mathrm{~h}$. Afterwards, populations either remained stable (cheeses SA1) or decreased slightly (cheeses SA3 and SA2) during ripening.

Staphylococcus-specific SSCP patterns of DNA extracted from coagulated milk were different for each cheese production SA1, SA2 and SA3 (Fig. 3A-C) and comprised three to four main peaks (peaks a-d) with various relative intensities. Patterns from milks SA1 and SA3 were similar, comprising peaks a, c and $\mathrm{d}$ in different ratios. The pattern from milk SA2 distinguished itself by the presence of one additional peak (peak b). Dramatic changes in peak ratio were observed on patterns from 12-h cheeses: peak ' $a$ ' became dominant in the three cheese productions (Fig. 3D). No more shift in peak ratio was observed during ripening (28-day cheese, Fig. 3E).

Most of the peaks were identified by comparison with the patterns of the reference species. Peak a/a' was found to correspond to the $S$. aureus pattern. Peak c comigrated with the $S$. saprophyticus pattern and peak d with the $S$. equorum pattern. Peak b did not correspond to any species included in our reference.

In order to confirm this identification through a direct approach, the nested SSCP-PCR products of the coagulated milk and the 28-day cheese from farm SA1 were cloned. Twenty-five clones were analysed by the nested SSCP-PCR assay. Twenty isolates of coagulase-positive staphylococci were also randomly picked from count plates of cheeses from the three farms and subjected to SSCP-PCR analysis. All SSCP patterns from clones and isolates were found to comigrate with the $S$. aureus pattern and with peak 'a' of the cheese patterns, and 16S rDNA sequences all corresponded to $S$. aureus $16 \mathrm{~S}$ rDNA (ATCC 700699, Genbank accession number AP003363).

\section{DISCUSSION}

This study describes the development of a Staphylococcus genus-specific SSCP-PCR assay used to investigate the diversity and dynamics of Staphylococcus populations during cheese making. To our knowledge, this is the first report of specific amplification of the Staphylococcus genus directly from food samples and not from isolates.

Through analysis by the nested SSCP-PCR approach, $S$. aureus gave a two-peak SSCP pattern with a dominant peak. This may be because of intraspecies $16 \mathrm{~S}$ rRNA operon sequence heterogeneity or to different conformations of the same sequence (Coenye and Vandamme 2003). When applying the PCR assay on an artificial mixture of equal amounts of total DNA from seven species, a higher signal corresponding to $S$. aureus was noticed. This discrepancy may result from preferential amplification of $S$. aureus $16 \mathrm{~S}$ rRNA gene, differences in genome size of the different species or interspecies $16 \mathrm{~S}$ rRNA operon copy number heterogeneity (Coenye and Vandamme 2003). According to currently available data about $16 \mathrm{~S}$ rRNA operon copy number in the Staphylococcus genus, four copies were detected in Staphylococcus carnosus strain TM300, five copies in Staphylococcus epidermidis strain PCI 1200, five in $S$. aureus strains Mu50 and N315, and six in S. aureus strains MW2 and BB255 (Klappenbach et al. 2001). These observations point out the limits of the SSCP approach and have to be carefully considered while interpreting the results. 

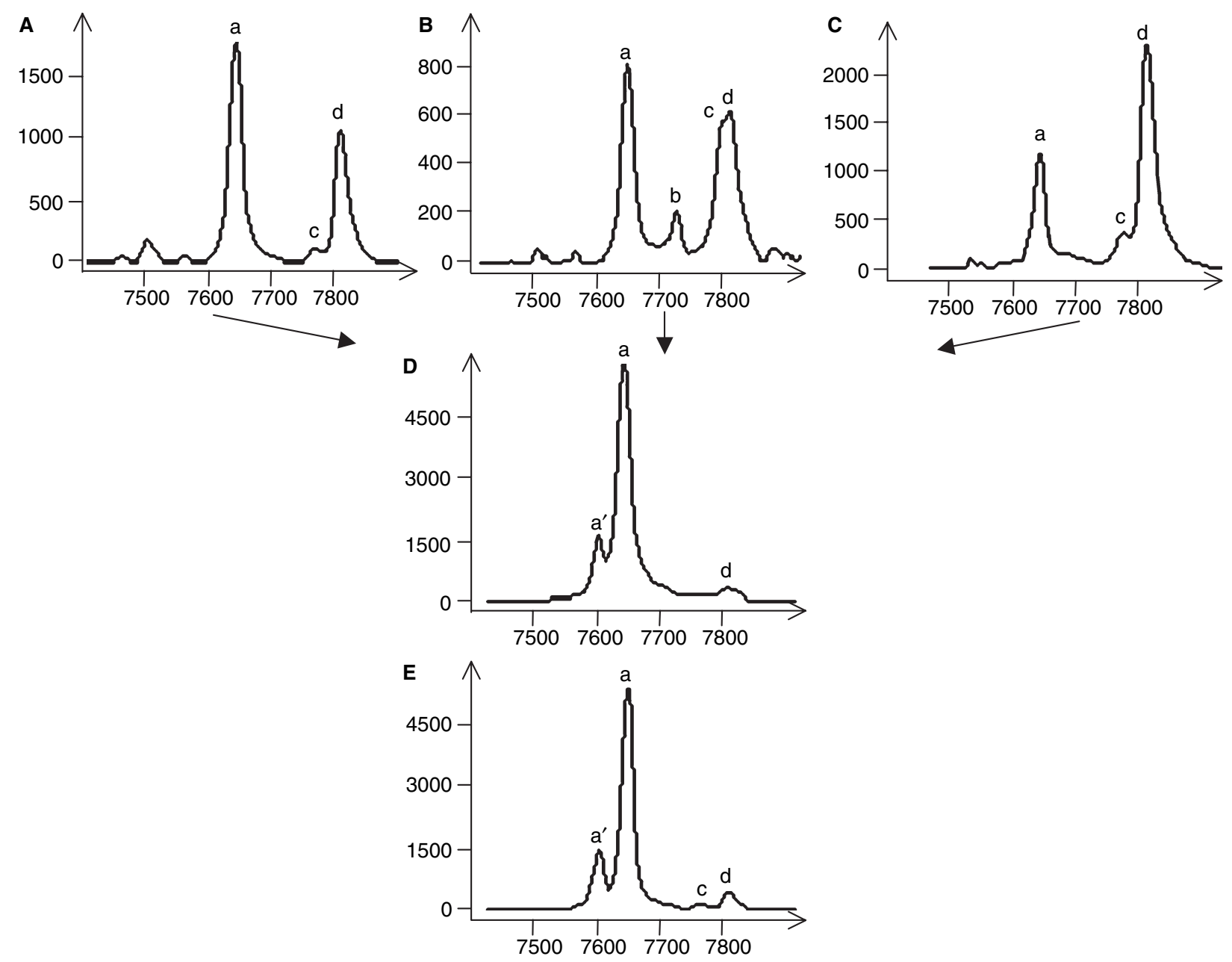

Fig. 3 SSCP patterns obtained after specific amplification of Staphylococcus genus 16S rRNA genes from milk and cheeses at different stages of ripening (forward strand of amplicon). (A-C) Coagulated milk from farms SA1, SA2 and SA3 respectively; (D) representative pattern of cheeses SA1, SA2 and SA3 at 12 h; (E) representative pattern of cheeses SA1, SA2 and SA3 at 28 days. Peaks a, a': S. aureus; peak b: unidentified; peak c: $S$. saprophyticus; peak d: $S$. equorum

Analysis of the V2 region of the $16 \mathrm{~S}$ rRNA gene discriminated the staphylococcal species most frequently found in cheese. Other regions of the 16S rRNA gene were not discriminative enough (Takahashi et al. 1999; Ercolini et al. 2003). The nested PCR-SSCP approach was efficient in distinguishing species such as $S$. xylosus, $S$. equorum and $S$. saprophyticus, for which phenotypic identification is problematic (Irlinger et al. 1997; Morot-Bizot et al. 2003).

Apart from $S$. aureus, $S$. equorum was the second species of Staphylococcus detected by SSCP-PCR in milk from all three farms. Staphylococcus saprophyticus was also found at a lower level. We did not find any of the other species used as reference at detectable levels. This diversity of species closely matches the results of conventional or molecular studies in other cheeses, that found $S$. equorum as the prevailing coagulase-negative Staphylococcus in cheese, followed by
S. xylosus, S. saprophyticus and S. vitulinus (Irlinger et al. 1997; García et al. 2002; Ercolini et al. 2003). Our approach has several advantages. It is independent of strain isolation, gives a direct pattern of Staphylococcus populations and was efficient in showing the diversity of staphylococcal species present in each milk sample. As a consequence of the possible bias in favour of $S$. aureus as discussed above, peak ratios between the different species from an isolated pattern should be considered cautiously. However, this bias does not prevent the drawing up of conclusions from changes in these ratios in respect to population dynamics. Successive SSCP patterns revealed marked population dynamics with a major increase in $S$. aureus population ratio from milk to cheese at $12 \mathrm{~h}$. This observation was corroborated by the growth kinetics of coagulase-positive staphylococci, as determined on plated medium. 
In conclusion, our results suggest that in the core of the cheeses studied, $S$. aureus may have ecological advantages against other Staphylococcus populations. The strategy described in the present study allows direct monitoring of staphylococci diversity and dynamics in ecosystems in which these populations can be subdominant, such as milk and cheese. Combined with real-time PCR for a more accurate and culture-independent quantification of Staphylococcus populations, this approach may be a helpful tool to study the ecology of staphylococci on the cheeses surface, where coagulase-negative staphylococci grow more particularly (Irlinger et al. 1997) and in other food samples.

\section{ACKNOWLEDGEMENTS}

We are grateful to Françoise Irlinger for providing Staphylococcus strains and to Nadia Chougui. We thank René Lavigne, colleagues from the Syndicat du Saint-Nectaire and the farmers for their collaboration.

\section{REFERENCES}

Coenye, T. and Vandamme, P. (2003) Intragenomic heterogeneity between multiple $16 \mathrm{~S}$ ribosomal RNA operons in sequenced bacterial genomes. FEMS Microbiol Lett 228, 45-49.

Coppola, S., Blaiotta, G., Ercolini, D. and Moschetti, G. (2001) Molecular evaluation of microbial diversity occurring in different types of Mozzarella cheese. 7 Appl Microbiol 90, 414-420.

Couto, I., Pereira, S., Miragaia, M., Sanches, I.S. and de Lencastre, H. (2001) Identification of clinical staphylococcal isolates from humans by internal transcribed spacer PCR. F Clin Microbiol 39, 3099-3103.

De Buyser, M.L., Lombard, B., Schulten, S.M., In't Veld, P.H., Scotter, S.L., Rollier, P. and Lahellec, C. (2003) Validation of EN ISO standard methods 6888. Part 1 and Part 2: 1999 - Enumeration of coagulase-positive staphylococci in foods. Int 7 Food Microbiol 83, 185-194.

Devriese, L.A. and De Keyser, H. (1980) Prevalence of different species of staphylococci on teats and in milk samples from dairy cows. 7 Dairy Res 47, 155-158.

Duthoit, F., Godon, J.J. and Montel, M.C. (2003) Bacterial community dynamics during production of registered designation of origin salers cheese as evaluated by $16 \mathrm{~S}$ rRNA gene single strand conformation polymorphism analysis. Appl Environ Microbiol 69, 3840-3848.

Ercolini, D., Hill, P.J. and Dodd, C.E.R. (2003) Bacterial community structure and location in stilton cheese. Appl Environ Microbiol 69 , 3540-3548.
García, M.C., Rodríguez, M.J., Bernardo, A., Tornadijo, M.E. and Carballo, J. (2002) Study of enterococci and micrococci isolated throughout manufacture and ripening of San Simón cheese. Food Microbiol 19, 23-33.

Irlinger, F., Morvan, A., El Sohl, N. and Bergere, J.L. (1997) Taxonomic characterization of coagulase-negative staphylococci in ripening flora from traditional French cheeses. Syst Appl Microbiol 20, 319-328.

Klappenbach, J.A., Saxman, P.R., Cole, J.R. and Schmidt, T.M. (2001) rrndb: The ribosomal RNA operon copy number database. Nucleic Acids Res 1, 181-184.

Maidak, B.L., Cole, J.R., Parker, C.T., Garrity, G.M., Larsen, N., Li, B., Lilburn, T.G., McCaughey, M.J. et al. (1999) A new version of the RDP (Ribosomal Database Project). Nucleic Acids Res 27, 171173.

Mason, W.J., Blevins, J.S., Beenken, K., Wibowo, N., Ojha, N. and Smeltzer, M.S. (2001) Multiplex PCR protocol for the diagnosis of staphylococcal infection. 7 Clin Microbiol 39, 3332-3338.

Meyrand, A., Boutrand-Loei, S., Ray-Gueniot, S., Mazuy, C., Gaspard, C.E., Jaubert, G., Perrin, G., Lapeyre, C. et al. (1998) Growth and enterotoxin production of Staphylococcus aureus during the manufacture and ripening of Camembert-type cheeses from raw goats' milk. I Appl Microbiol 85, 537-544.

Morot-Bizot, S., Talon, R. and Leroy-Setrin, S. (2003) Development of specific PCR primers for a rapid and accurate identification of Staphylococcus xylosus, a species used in food fermentation. 7 Microbiol Methods 55, 279-286.

Ogier, J.C., Son, O., Gruss, A., Tailliez, P. and Delacroix-Buchet, A. (2002) Identification of the bacterial microflora in dairy products by temporal temperature gradient gel electrophoresis. Appl Environ Microbiol 68, 3691-3701.

Randazzo, C.L., Torriani, S., Akkermans, A.D.L., de Vos, W.M. and Vaughan, E.E. (2002) Diversity, dynamics, and activity of bacterial communities during production of an artisanal sicilian cheese as evaluated by $16 \mathrm{~S}$ rRNA analysis. Appl Environ Microbiol 68, 18821892.

Takahashi, T., Satoh, I. and Kikuchi, N. (1999) Phylogenetic relationships of 38 taxa of the genus Staphylococcus based on $16 \mathrm{~S}$ rRNA gene sequence analysis. Int $\mathcal{7}$ Syst Bacteriol 49, 725-728.

Vandecasteele, S.J., Peetermans, W.E., Merckx, R. and Van Eldere, J. (2001) Quantification of expression of Staphylococcus epidermidis housekeeping genes with Taqman quantitative PCR during in vitro growth and under different conditions. 7 Bacteriol 183, 70947101.

Vernozy-Rozand, C., Mazuy, C., Perrin, G., Haond, F., Bes, M., Brun, Y. and Fleurette, J. (1996) Identification of Micrococcaceae isolated from goat's milk and cheese in the Poitou-Charente region. Int 7 Food Microbiol 30, 373-378. 